\title{
A Theoretical Study of the Solid Solution Phases of $\mathrm{Li}_{x} \mathrm{FePO}_{4}$
}

\author{
Jun Yu ${ }^{1}$, Shaorui Sun ${ }^{2}$ \\ ${ }^{1}$ Institute of Chemistry\& Chemical Engineering, Qinghai University for Nationalities, Xining, China \\ ${ }^{2}$ Beijing Key Laboratory for Green Catalysis and Separation, College of Environmental and Energy Engineering, Beijing University of \\ Technology, Beijing, China
}

Email address:

yujuny@126.com (Jun Yu)

\section{To cite this article:}

Jun Yu, Shaorui Sun. A Theoretical Study of the Solid Solution Phases of $\mathrm{Li}_{\mathrm{x}} \mathrm{FePO}_{4}$. American Journal of Physical Chemistry. Vol. 9, No. 4, 2020, pp. 93-100. doi: 10.11648/j.ajpc.20200904.12

Received: November 2, 2020; Accepted: November 16, 2020; Published: November 24, 2020

\begin{abstract}
For the next generation Li-battery anode materials $\mathrm{LiFePO}_{4}$, the forming of the solid solution phase $\mathrm{Li}_{\mathrm{x}} \mathrm{FePO} \mathrm{P}_{4}$ and the related charge/discharge mechanism are the high light topics recently. In the paper, ab-initio calculation was applied to study the formation and electronic structure of the solid solution of $\mathrm{Li}_{\mathrm{x}} \mathrm{FePO} 4$, and a Charge/Discharge model of $\mathrm{LiFePO}_{4}$ was set up based on the calculation results. Due to the high formation energy, $\mathrm{Li}_{\mathrm{x}} \mathrm{FePO}_{4}$ separates into $\mathrm{FePO}_{4}$ and $\mathrm{LiFePO}_{4}$ in bulk system under room temperature. The single solid solution phase $\mathrm{Li}_{\mathrm{x}} \mathrm{FePO}_{4}$ could exists in the nanoscale particle, and it is due to that the relative larger lattice mismatch energy. The nanoscale particle materials should have a good rating performance due to the forming of $\mathrm{Li}_{\mathrm{x}} \mathrm{FePO}_{4}$ in solid solution phase, of which the partially occupied state and the small energy gap between the VBM and the defect state could improve the intrinsic electronic conductivity. In bulk materials, the medium region, which is composed of $\mathrm{Li}_{\mathrm{x}} \mathrm{FePO}_{4}$, is very narrow between the two phases $\mathrm{FePO}_{4}$ and $\mathrm{LiFePO}_{4}$. There is a electron potential well in the region, of which the bottom is at the side of $\mathrm{Li}_{\mathrm{x}} \mathrm{FePO}_{4}(\mathrm{x}<0.5)$. The number of electron in the well highly affects the lithium insertion and extraction. In order to efficiently transfer the electron between the potential well and the out circuit, an electron conductor network or layer should be coated on the $\mathrm{LiFePO}_{4}$ particle.
\end{abstract}

Keywords: $\mathrm{LiFePO}_{4}$, Solid Solution Phase, The Charge/Discharge Model

\section{Introduction}

As an alternative next generation cathode materials of lithium ion batteries, $\mathrm{LiFePO}_{4}$ have several advantages compared with conventional cathodes: lower cost, more safety, lower toxicity, and a reasonable high potential. While the poor intrinsic electronic conductivity and poor rate performance still limit its commercial application. Now the first problem has been solve by adding the conductive phase, typically carbon, which led to a room temperature capacity up to 160 $\mathrm{mAhg}^{-1}$. [1-8] The second problem is mainly attributed to the $\mathrm{FePO}_{4} / \mathrm{LiFePO}_{4}$ two-phase charge/discharge mechanism which is firstly mentioned by Yamada and co-workers. $[9,10]$

Until now, several works have been carried out to understand the lithium intercalation and deintercalation reactions. The theoretical studies reported by Morgan et. al., [11] Ouyang et. al. [12] and Islam et. al. [13] showed that $\mathrm{LiFePO}_{4}$ is an one-dimensional ionic conductor, and the lithium ions only migrate along the [10] direction, and the conclusion was confirmed with the neutron diffraction technique by Nishimura et. al. [14] Ellis et. al. measured the active energy of the electron migration coupled with the lithium ion is $775 \pm 108 \mathrm{meV}$ with the mössbauer spectra, [15] and the value well agree with that predicted by Maxisch et. al. through the first principal calculation method. [16]

Yamada has reported an incomplete miscibility gap at room temperature and the corresponding solid solutions $\mathrm{Li}_{\mathrm{x}} \mathrm{FePO}_{4}$ $(0<x<\alpha$, and $1-\beta<x<1),[10,17]$ and for the bulk or large-sized materials, the values of $\alpha$ and $\beta$ are very small. [18] Laffont et. al. observed the narrow mismatch zone between the two end phases $\left(\mathrm{Li}_{\alpha} \mathrm{FePO}_{4}\right.$ and $\left.\mathrm{Li}_{1-\beta} \mathrm{FePO}_{4}\right)$ with the electron energy-loss spectroscopy (EELS) technique. [19] Chen et. al. carried out an electron microscopy study of $\mathrm{Li}_{0.5} \mathrm{FePO}_{4}$, which is a 1:1 mixture of $\mathrm{LiFePO}_{4}$ and $\mathrm{FePO}_{4}$, and they reported that 
lithium is deintercalated at the phase boundary of the two phase parallel to the $b c$ plane which progresses in the $a$ direction. [20] Allen et. al. carried out a simulation of the lithium intercalation with the Avrami-Johnson-Mehl-Eroofev equation, and showed that the active energy of the $\mathrm{Li}_{\alpha} \mathrm{FePO}_{4}$ to $\mathrm{Li}_{1-\beta} \mathrm{FePO}_{4}$ phase transformation is about $13 \mathrm{kJmol}^{-1}$ (about $130 \mathrm{meV}$ per formula), which is very small. [21] Delmas et. al. constructed an elegant charge/discharge model based on their X-ray diffraction (XRD) and high-resolution electron diffraction, in which the mismatch zone between the two end phases is solid solution in the miscibility gap, and plays the key role in the cathode electrochemical reaction. [22]

Although there is very limited solid solution (in the miscibility gap) zone in the bulk or large-sized system under ambient condition, the single solid solution phase $\mathrm{Li}_{\mathrm{x}} \mathrm{FePO}_{4}$ over the entire compositional domain $(0<\mathrm{x}<1)$ is observed when the temperature is above $520 \mathrm{~K}$. [23, 24] Gibot et. al. reported that single-phase lithium insertion/extraction in 40-nm $\mathrm{Li}_{\mathrm{x}} \mathrm{FePO}_{4}$ particle under room-temperature. [25] Kobayashi et. al. confirmed the results and mentioned that the miscibility is depended on the particle size. [18] The two works show that single solid solution phase $\mathrm{Li}_{\mathrm{x}} \mathrm{FePO}_{4}$ over the entire compositional domain $(0<\mathrm{x}<1)$ exists in the nanoscale particles and change the two-phase charge/discharge mechanism of $\mathrm{LiFePO}_{4}$ into single-phase mechanism under room-temperature, which maybe is an effective way to improve the $\mathrm{LiFePO}_{4}$ 's electrochemical performance.

In the paper, we carried out the first principal calculation to study the solid solution phase of $\mathrm{Li}_{\mathrm{x}} \mathrm{FePO}_{4}(0<\mathrm{x}<1)$. For the nanoscale particle, the work maybe improve people to understand the single-phase charge/discharge mechanism on the electronic-scale level; for the bulk or large-sized system, it is also helpful to discover the function of the solid solution in the mismatch zone between the two end phases $\left(\mathrm{Li}_{\alpha} \mathrm{FePO}_{4}\right.$ and $\left.\mathrm{Li}_{1-\beta} \mathrm{FePO}_{4}\right)$ in the two-phase charge/discharge process.

The paper is organized as the follows: in part II, the calculation method and the crystal structure are discribed; in part III, the formation of the $\mathrm{Li}_{\mathrm{x}} \mathrm{FePO}_{4}$ solid solution phase is discussion; in part IV, the electronic structure of the solution phase is studied; in part $\mathrm{V}$, the charge/discharge mechanisms of the nanoscale particle matterials and bulk materials is studied; in part VI, the summary is presented.

\section{Calculation Method and Crystal Structure}

The density functional theory (DFT) calculations report in this work were performed using the VASP (Vienna Ab-initio Simulation Package) code, and the projected-augmented wave (PAW) approach was implemented to treat the ion-electron interactions. The exchange-correlation energy of electrons was described in the generalized gradient approximation (GGA) with the functional parameterization of PBE. The energy cut-off was set at $400 \mathrm{eV}$, and a criterion of at least $0.0001 \mathrm{eV} /$ atom was placed on the self-consistent convergence of the total energy.
In the previous theoretical works, the calculation results with LDA (local density approximation) or GGA (generalized gradient approximation) show that the band gap of $\mathrm{LiFePO}_{4}$ is about $0.2 \mathrm{eV}$, which is very largely underestimated the gap value of 3.8-4.0 eV measured in experimental works, and it implies that LDA and GGA are not reasonable to be implemented to investigate $\mathrm{LiFePO}_{4}$. While $\mathrm{LDA}+\mathrm{U}$ or $\mathrm{GGA}+\mathrm{U}$ could take into account the strong correlation between the $\mathrm{Fe}-3 \mathrm{~d}$ electrons, and some previous works with this method has successfully predicted the band gap which is well consistent with the experimental values. The in the work, we applied the GGA+U method to the two Iron-based Phosphate Cathode Materials, and the value of $\mathrm{U}_{\text {eff }}(=\mathrm{U}-\mathrm{J})$ for the Fe-3d orbital is set as $4.3 \mathrm{eV}$.

The space group of the $\mathrm{LiFePO}_{4}\left(\right.$ or $\left.\mathrm{FePO}_{4}\right)$ is Pnma, and lithium ions occupy $4 a$ sites: $(0,0,0),(05,0,0.5),(0.5,0.5$, $0.5)$ and $(0,0.5,0)$, which are the intermediate sites in the framework formed the $\mathrm{FeO}_{6}$ octahedrons and $\mathrm{PO}_{4}$ tetrahedrons as shown in Figure 1(a). After geometry optimizations, the values of lattice constants of $\mathrm{LiFePO}_{4}$ $\left(\mathrm{FePO}_{4}\right)$ are $\mathrm{a}=10.43(9.94) \AA, \mathrm{b}=6.02$ (5.89) $\AA$, and $\mathrm{c}=4.72$ (4.83) $\AA$ respectively, which are well coincided the experimental values. In order to simplify the calculations for $\mathrm{Li}_{\mathrm{x}} \mathrm{FePO}_{4}$, the cases of $\mathrm{x}=0.25,0.5$ and 0.75 are selected, and the calculations are performed in one primitive cell including four formula. For $\mathrm{Li}_{0.75} \mathrm{FePO}_{4}$, three of $4 a$ sites are placed with lithium ions, and one with vacancy (shown in Figure 1(b)); similarly for $\mathrm{Li}_{0.25} \mathrm{FePO}_{4}$, three of $4 a$ sites are placed with vacancy, and one with lithium ions (shown in Figure 1(d)). While for $\mathrm{Li}_{0.5} \mathrm{FePO}_{4}$, there are three different configurations, and taken into account the Coulomb interaction between the lithium ions, the two sites with largest distance, $(0,0,0)$ and $(0.5,0.5,0.5)$, are occupied by lithium ions (shown in Figure 1(d)). Considered that the lithium and vacancy randomly distribute in crystal lattice, $\mathrm{Li}_{\mathrm{x}} \mathrm{FePO}_{4}$ is kept as tetragonal system in the geometrical optimization process.

(a)

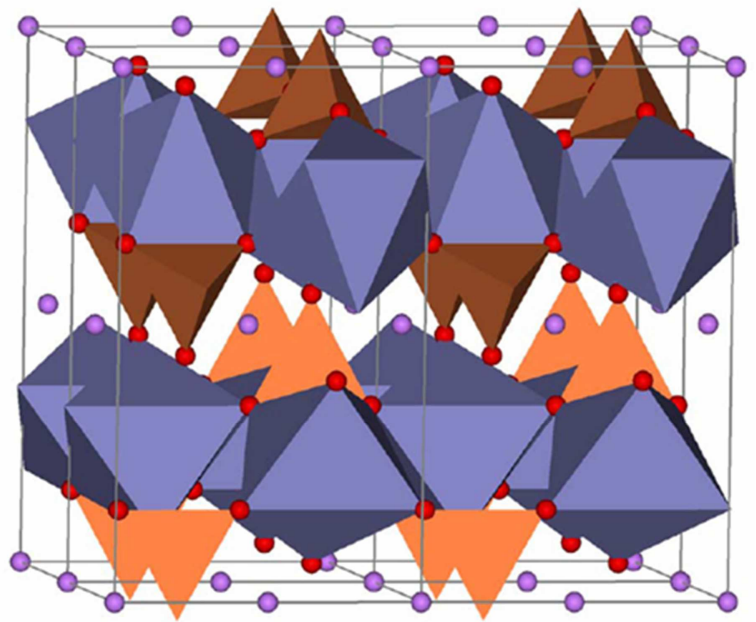


(b)

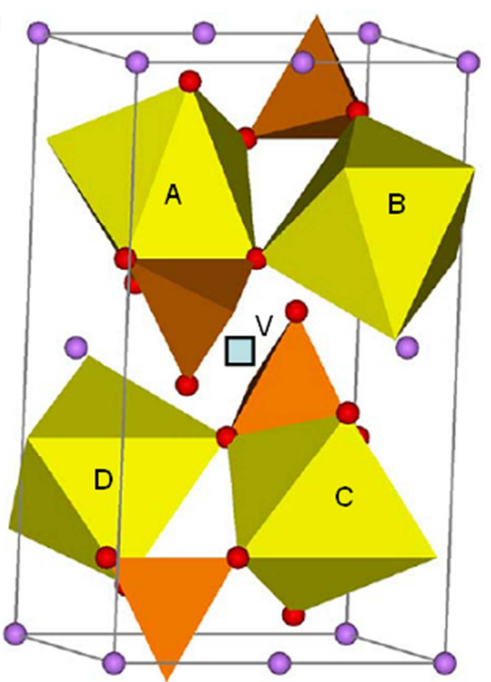

(c)

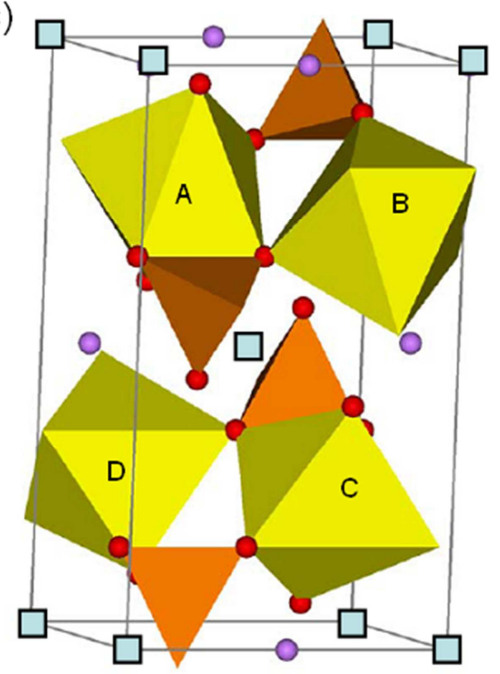

(d)

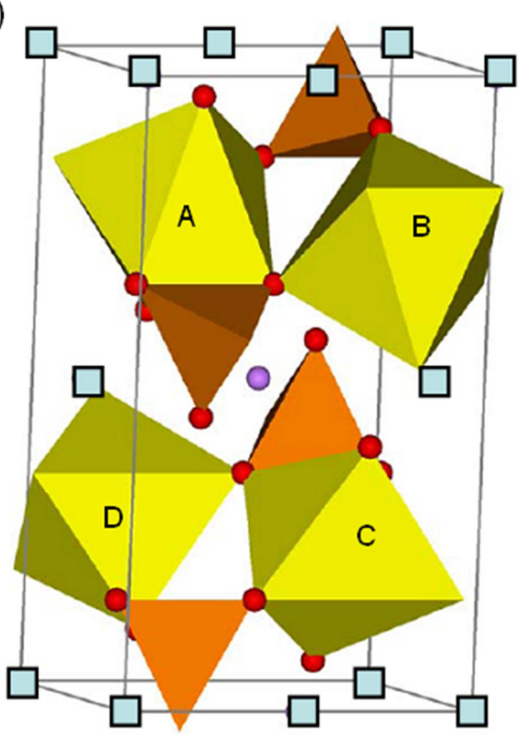

Figure 1. (a) the structure of $\mathrm{LiFePO}_{4}$, in which lithium are the intermediate sites in the framework formed the $\mathrm{FeO}_{6}$ octahedrons and $\mathrm{PO}_{4}$ tetrahedrons; (b) the structure of $\mathrm{Li}_{0.75} \mathrm{FePO}_{4}$, in which the square is the vacancy; (c) the structure of $\mathrm{Li}_{0.50} \mathrm{FePO}_{4}$; (d) the structure of $\mathrm{Li}_{0.25} \mathrm{FePO}_{4}$

\section{Formation of the Solution Phase}

When two isolated phases form a solution phase, the change in Gibbs free energy is defined as:

$$
\Delta G=\Delta E+P \Delta V-T \Delta S
$$

Where $\Delta E$ is the internal energy, $P$ is the pressure, $\Delta V$ is the volume change, $T$ is the temperature, and $\Delta S$ is the change in entropy.

Under the room temperature, $\mathrm{FePO}_{4}$ and $\mathrm{LiFePO}_{4}$, and their solution phase $\mathrm{Li}_{x} \mathrm{FePO}_{4}$ are all in solid states. The volume change $\Delta V$ is very small and does not largely affect the Gibbs free energy largely, and then the second term is negligible in the work.

The value of $\Delta E$ could be got from the total energies of different phase with the ab-initio calculations, between $\mathrm{Li}_{x} \mathrm{FePO}_{4}$ and the two end phase: $\mathrm{FePO}_{4}$ and $\mathrm{LiFePO}_{4}$, the change in the total energy per formula is (The change of the crystal lattice vibration energy is very small compared with $\Delta E$, and is neglected here):

$$
\Delta E_{x}=E_{x}-\left[x E_{1}+(1-x) E_{0}\right]
$$

where $x$ is the lithium number per formula (the lithium concentration), and $E_{x}$ is the total energy per formula of $\mathrm{Li}_{x} \mathrm{FePO}_{4}, E_{1}$ is that of $\mathrm{LiFePO}_{4}$, and $E_{0}$ is that of $\mathrm{FePO}_{4}$ (compared with the above energy, the phonon energy is very small, and is neglected here). The lithium concentration dependence of $\Delta E$ is shown in figure 2 . The horizontal line at $\Delta E=0$ is for the mixture with a various ratio as $x / 1-x$ of $\mathrm{LiFePO}_{4}$ and $\mathrm{FePO}_{4}$. It is clearly that the values of $\Delta E_{x}$ $(\mathrm{x}=0.25,0.50$ and 0.75$)$ are all positive.

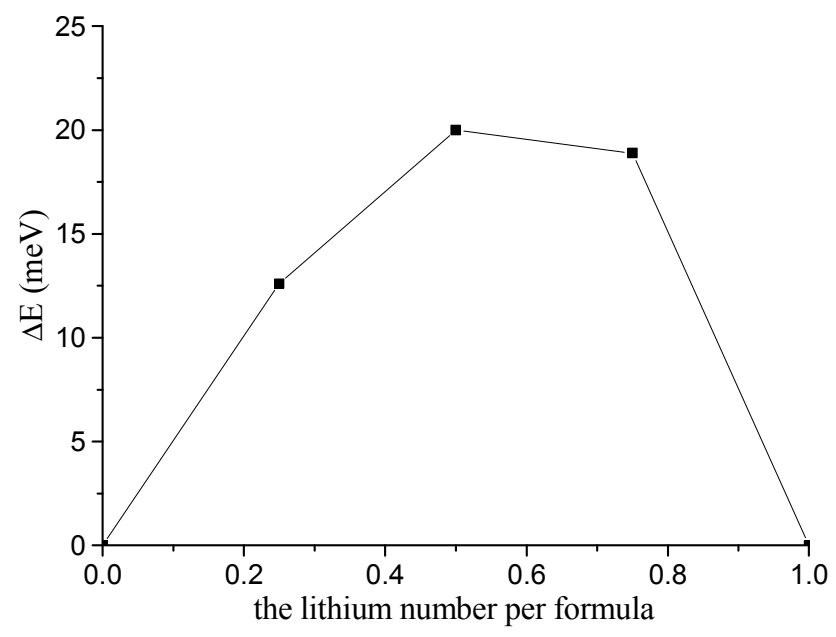

Figure 2. The lithium concentration dependence of $\Delta E$.

The change of entropy $\Delta S$ is attributed into two parts: the change in the configuration entropy, $\Delta S_{\text {conf; }}$; and that in the vibration entropy, $\Delta S_{\text {vib. }}$. The configuration entropy of a disordered solid solution of solute concentration, $c$, is calculated as:

$$
S_{\text {conf }}=-k_{B}[(1-c) \ln (1-c)+c \ln c]
$$


where $k_{\mathrm{B}}$ is Boltzmann constant, and for $\mathrm{Li}_{\mathrm{x}} \mathrm{FePO}_{4}$, the value of concentration is $x$. $S_{\text {conf }}$ of the separated phases, $\mathrm{FePO}_{4}$ and $\mathrm{LiFePO}_{4}$, is zero. $S_{\text {conf }}$ of $\mathrm{Li}_{0.25} \mathrm{FePO}_{4}, \mathrm{Li}_{0.50} \mathrm{FePO}_{4}$ and $\mathrm{Li}_{0.75} \mathrm{FePO}_{4}$ are $4.67,5.76$ and $4.67 \mathrm{~J} /(\mathrm{K} \cdot \mathrm{mol})$, respectively. Under the room temperature $(\mathrm{T}=300 \mathrm{~K})$, the values of $T \Delta S_{\text {conf }}$ are $1.40,1.73$ and $1.40 \mathrm{~kJ} / \mathrm{mol}$, i.e. $1.5 \mathrm{meV}, 1.8 \mathrm{meV}$ and 1.5 meV per formula, respectively.

$$
S_{v i b}=3 k_{B} \int_{0}^{\infty}[(1+n) \ln (1+n)-n \ln (n)] g(E) d E
$$

where $n$ is the plank distribution, and $g(E)$ is the phonon DOS (Density of State). Due to that the phonon DOS calculation is too slow, it is not performed in the work. According to the experimental results reported by Stevens et. al., at $473 \mathrm{~K}$, the value of $T \Delta S_{v i b}$ is $0.54 \pm 0.27 \mathrm{~kJ} / \mathrm{mol}$, i.e. $0.56 \pm 0.28 \mathrm{meV}$. The results demonstrate that the value of $T \Delta S_{\text {conf }}$ or $T \Delta S_{\text {vib }}$ is largely smaller than that of $\Delta E$, and the change of $\Delta G$ is mainly determined by $\Delta E$.

The result of $\Delta E$ well agrees with that reported by Zhou et. al., [26] which means that the calculation of the work is reliable. Zhou et. al. also considered the electron configuration entropy in another work, [27] in which result show that under room temperature, $\mathrm{Li}_{x} \mathrm{FePO}_{4}$ separated into the two phases: $\mathrm{LiFePO}_{4}$ and $\mathrm{FePO}_{4}$, and it does not conflict the results in the paper.

\section{DOS of the Solution Phase}

The DOS (Density of State) of $\mathrm{Li}_{x} \mathrm{FePO}_{4}(\mathrm{x}=1.00,0.75$, $0.50,0.25,0)$ are shown Figure 3 (a), (b), (c), (d) and (e), respectively. In $\mathrm{Li}_{\mathrm{x}} \mathrm{FePO}_{4}$, phosphorus is at the center of the $\mathrm{PO}_{4}$ tetrahedron, and its $3 \mathrm{~s}$ state is strongly localized, which is not largely affected by the lithium insertion/extraction. Then the center of the energy level of P-3s is set as the reference energy $(0 \mathrm{eV})$. For $\mathrm{LiFePO}_{4}$, the iron is with +2 , and the configure of Fe-3d state is $\left(3 \mathrm{~d}_{5.0}\right) \uparrow\left(3 \mathrm{~d}_{1.0}\right) \downarrow$, and the $\gamma$ state (shown in Figure 3. (a)) is fully occupied by the minority spin electrons; for $\mathrm{FePO}_{4}$, the iron is with +3 charge, and the configuration is $\left(3 \mathrm{~d}_{5.0}\right) \uparrow$. There are no partially occupied bands in the two end phases, and they are insulators or semiconductors with large band gap.

$\mathrm{Li}_{0.75} \mathrm{FePO}_{4}$ could be looked as a lithium extracted from a unit cell of $\mathrm{LiFePO}_{4}$ (containing four formula) as the structure shown in Figure 1(b). The two nearest irons around the vacancy are at $A$ and $C$ sites, respectively; the two next nearest irons are at $\mathrm{B}$ and $\mathrm{D}$, respectively. Accompanied with the lithium extraction, an electron is moved from the $\mathrm{LiFePO}_{4}$ unit cell. In Figure 3(b), two minority spin defects, $\alpha$ and $\beta$, are located in the energy gap, which are formed from the $\gamma$ state in the DOS of $\mathrm{LiFePO}_{4}$. The $\alpha$ state is exactly half occupied, and is attributed to the minority spin d-states of iron at $\mathrm{A}$ and $\mathrm{C}$ site. Then the electron at the Fermi level is not localized at one iron ion, but the two equivalent nearest iron: $\mathrm{A}$ and $\mathrm{C}$, and their $\mathrm{d}$-states configurations are both $\left(3 \mathrm{~d}_{5.0}\right) \uparrow\left(3 \mathrm{~d}_{0.5}\right) \downarrow$. The $\beta$ state is fully occupied, and is attributed to the minority spin d-states of iron at $B$ and $D$ site, which are the two next nearest sites around the lithium vacancy. Then for iron $\mathrm{B}$ and $\mathrm{D}$, the $\mathrm{d}$-states configurations are both $\left(3 \mathrm{~d}_{5.0}\right) \uparrow\left(3 \mathrm{~d}_{1.0}\right) \downarrow$.

In $\mathrm{Li}_{0.50} \mathrm{FePO}_{4}$, as shown in Figure 1(c), each iron is neighbored with two lithiums. The $\gamma$ state (in Figure 3(c)), which is fully occupied in Figure 3(a), is exactly half occupied here. It is attributed to the minority spin $3 \mathrm{~d}$ states of the four irons at A, B, C and D sites, which are all with the same d-state configuration as $\left(3 \mathrm{~d}_{5.0}\right) \uparrow\left(3 \mathrm{~d}_{0.5}\right) \downarrow$.
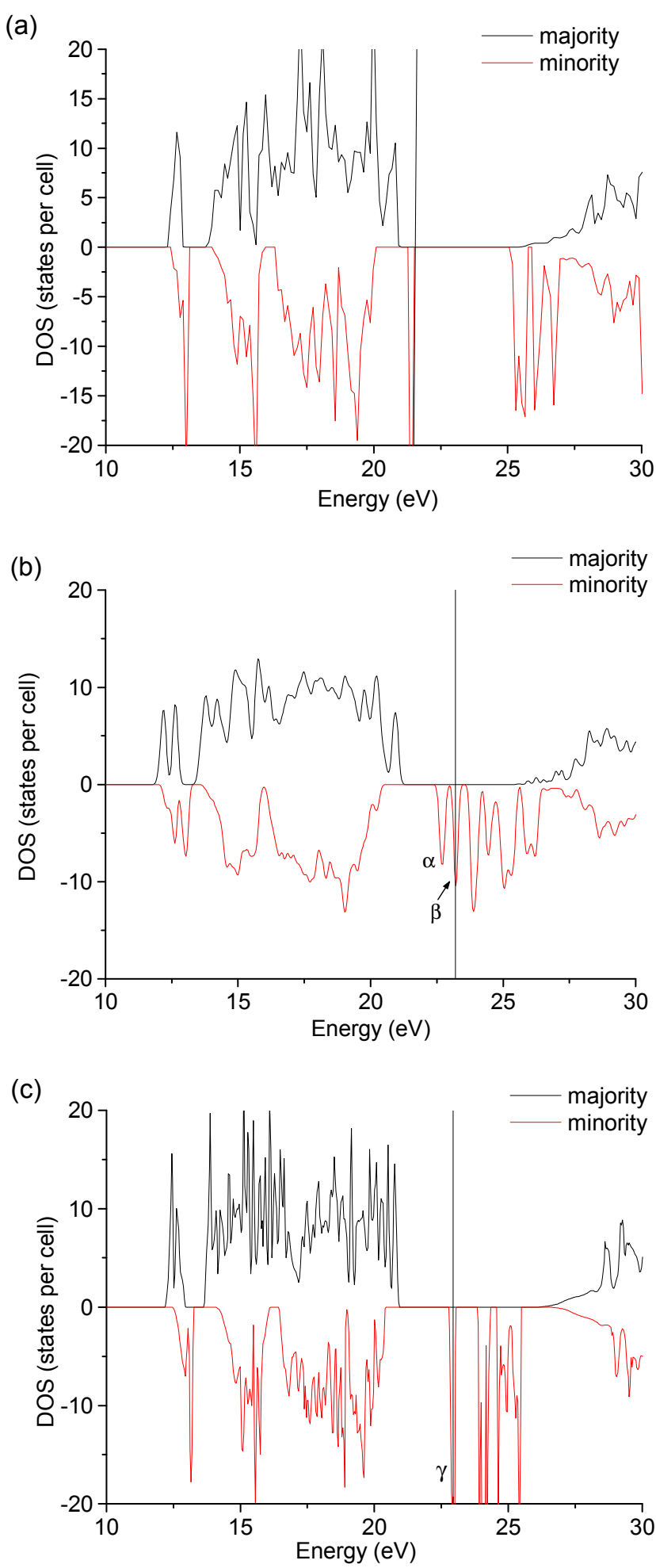
(d)

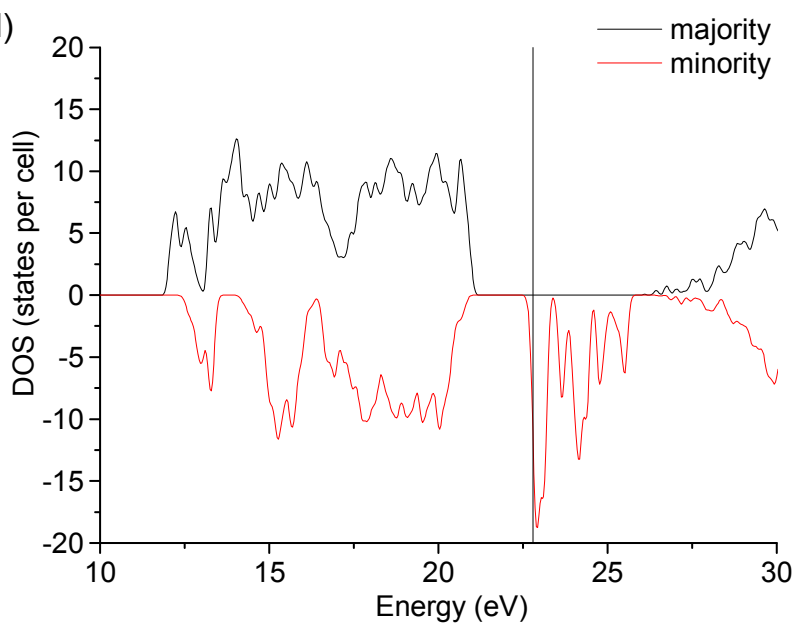

(e)

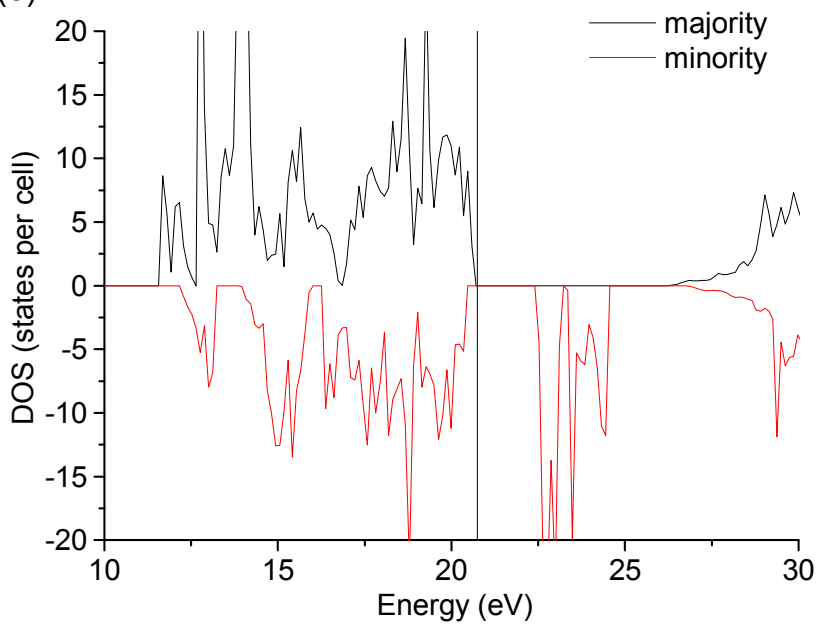

Figure 3. The DOS (Density of State) of (a) $\mathrm{LiFePO}_{4}$; (b) $\mathrm{Li}_{0.75} \mathrm{FePO}_{4}$; (c) $\mathrm{Li}_{0.50} \mathrm{FePO}_{4}$; (d) $\mathrm{Li}_{0.25} \mathrm{FePO}_{4}$; (e) $\mathrm{FePO}_{4}$.

$\mathrm{Li}_{0.25} \mathrm{FePO}_{4}$, as shown in Figure 1(d), contains one lithium and three vacancies. The two nearest irons around the lithium are at $\mathrm{A}$ and $\mathrm{C}$ sites, respectively; the two next nearest irons are at $\mathrm{B}$ and $\mathrm{D}$, respectively. The Fermi level is almost located at the bottom of the conduction band. The integral from the conduction bottom to the fermi level shows that just an electron is in the conduction band. Similar to $\mathrm{Li}_{0.75} \mathrm{FePO}_{4}$, the electron is not localized around one iron ion, but the two neatest iron $\mathrm{A}$ and $\mathrm{C}$, and the $\mathrm{d}$-states configuration of iron $\mathrm{A}$, B, C, and D are $\left(3 \mathrm{~d}_{5.0}\right) \uparrow\left(3 \mathrm{~d}_{0.5}\right) \downarrow,\left(3 \mathrm{~d}_{5.0}\right) \uparrow,\left(3 \mathrm{~d}_{5.0}\right) \uparrow\left(3 \mathrm{~d}_{0.5}\right) \downarrow$ and $\left(3 \mathrm{~d}_{5.0}\right) \uparrow$, respectively.

As presented in Figure 4, the Fermi energy level of $\mathrm{Li}_{\mathrm{x}} \mathrm{FePO}_{4}(\mathrm{x} \neq 0$ and $\neq 1)$ are all higher than that of either of the two end phases $\left(\mathrm{FePO}_{4}\right.$ and $\left.\mathrm{Li}_{\mathrm{x}} \mathrm{FePO}_{4}\right)$. This implies that the valence fluctuation phenomena and partially occupied states in $\mathrm{Li}_{\mathrm{X}} \mathrm{FePO}_{4}$ improve the electron kinetics energy, and it is one reason for the $\Delta E$ larger than zero. The other reason is that the random distribution of lithium and vacancy distort the crystal lattice, and improve the elastic energy.

As the former discussion, due to the high value of $\Delta E$, bulk $\mathrm{Li}_{\mathrm{x}} \mathrm{FePO}_{4}$ could not exist as a single solid solution phase, but separates into the two end phases: $\mathrm{FePO}_{4}$ and $\mathrm{LiFePO}_{4}$. Now the two end phases are commonly mentioned as $\mathrm{Li}_{\alpha} \mathrm{FePO}_{4}$ and $\mathrm{Li}_{1-\beta} \mathrm{FePO}_{4}$, which are very close to $\mathrm{FePO}_{4}$ and $\mathrm{LiFePO}_{4}$, respectively, due to the small values of $\alpha$ and $\beta$. Here in order to simplify the depiction, we only cite them as $\mathrm{FePO}_{4}$ and $\mathrm{LiFePO}_{4}$.

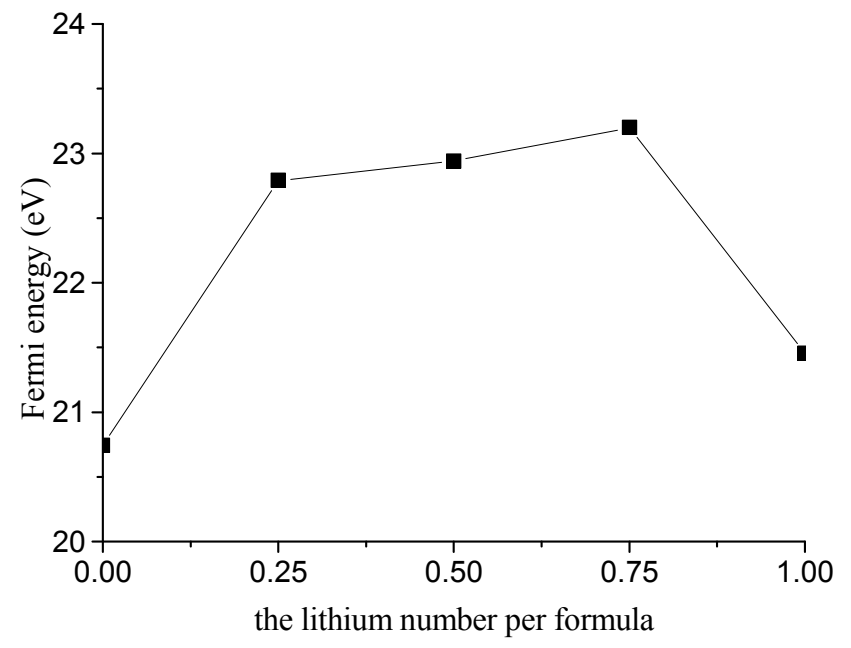

Figure 4. The lithium concentration dependence of the Fermi level.

Perpendicularly to the (100) axis, there is a very narrow medium region between the $\mathrm{FePO}_{4}$ and $\mathrm{LiFePO}_{4}$ phases, which is created from the large lattice mismatch as shown in Figure 5, because the medium region could lower the mismatch elastic energy. In the region, the composition of $\mathrm{Li}_{\mathrm{x}} \mathrm{FePO}_{4}$ rapidly changes from $\mathrm{Li}_{\alpha} \mathrm{FePO}_{4}$ to $\mathrm{Li}_{1-\beta} \mathrm{FePO}_{4}$. If the formation energy $\Delta E$ of $\mathrm{Li}_{x} \mathrm{FePO}_{4}$ is small, the mismatch energy could create a large medium region. Unfortunately, the formation energy is very large as the former discussion, and then the region is very narrow.

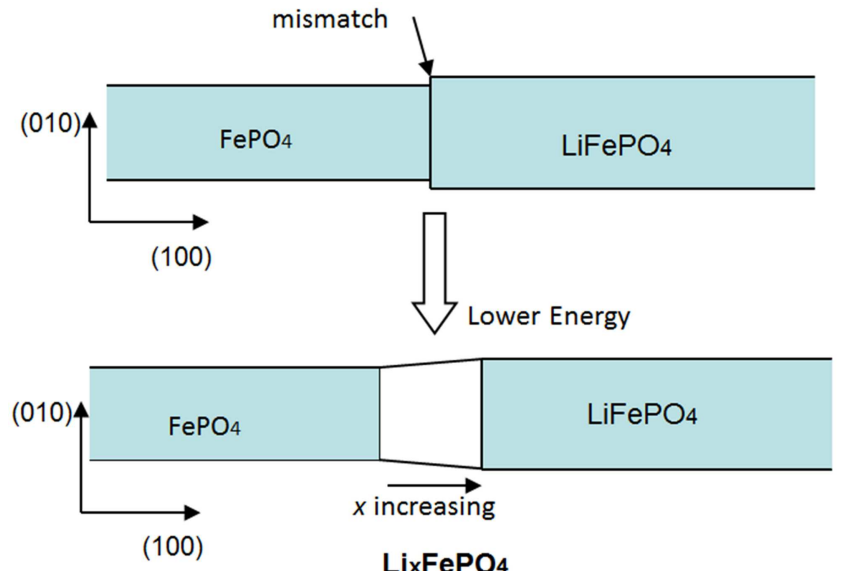

Figure 5. The lattice mismatch between $\mathrm{FePO}_{4}$ and $\mathrm{LiFePO}_{4}$, and the forming of the medium region between the two phase.

While for the nanoscale particle $\mathrm{Li}_{\mathrm{x}} \mathrm{FePO}_{4}$, if the contained number of the primary cell is small enough, the lattice mismatch energy maybe higher than the total formation energy of $\mathrm{Li}_{x} \mathrm{FePO}_{4}: \mathrm{n} \Delta E(\mathrm{n}$ is the number of the primary cell in the nanoscale particle), and $\mathrm{Li}_{x} \mathrm{FePO}_{4}$ does not separate into the two end phase $\left(\mathrm{FePO}_{4}\right.$ and $\left.\mathrm{LiFePO}_{4}\right)$, and could be a 
single solid solution phase. The research on $\mathrm{Li}_{\mathrm{x}} \mathrm{FePO}_{4}$ is still continuing. [28-30]

\section{Modeling of the Charge/Discharge Process}

\subsection{The Nanoscale Particle}

Compared with the DOS of $\mathrm{LiFePO}_{4}$ or $\mathrm{FePO}_{4}$, there are two significant characters of that of $\mathrm{Li}_{\mathrm{x}} \mathrm{FePO}_{4}$ : the first is that the Fermi level is through the half occupied defect states mainly due to the minority-spin electron states of Fe-3d; The second is that the gap between the VBM (valence band maxaium) and the defect state is obviously smaller than that of the band gap of $\mathrm{LiFePO}_{4}$ or $\mathrm{FePO}_{4}$. It implies that intrinsic electron conductivity of $\mathrm{Li}_{\mathrm{x}} \mathrm{FePO}_{4}$ is largely higher than that of $\mathrm{LiFePO}_{4}$ or $\mathrm{FePO}_{4}$. Then the nanoscale particle system has a good rating performance due to the solid solution phase of $\mathrm{Li}_{\mathrm{x}} \mathrm{FePO}_{4}$ forming in the charge/discharge process.

\subsection{The Bulk Materials}

For the bulk system, although the medium region between $\mathrm{LiFePO}_{4}$ and $\mathrm{FePO}_{4}$ is very narrow, it plays an important role in the lithium insertion/extraction process. In the medium region, $\mathrm{Li}_{\mathrm{x}} \mathrm{FePO}_{4}$ is only periodic in (010) and (001) direction, not in (100) direction, while the value of $x$ gradually change in (100) direction. Then the electronic structure calculation of $\mathrm{Li}_{\mathrm{x}} \mathrm{FePO}_{4}$ in an ideal three dimension crystal structure could be applied to make a qualitative study on the medium region between $\mathrm{LiFePO}_{4}$ and $\mathrm{FePO}_{4}$.

As shown in Figure 4, the Fermi level of $\mathrm{Li}_{x} \mathrm{FePO}_{4}(x>0.5)$, which is at the side close to $\mathrm{LiFePO}_{4}$, is higher than that of $\mathrm{Li}_{\mathrm{x}} \mathrm{FePO}_{4}(\mathrm{x}<0.5)$, which is close to $\mathrm{FePO}_{4}$. Then the electrons just below the Fermi level in the former will transit into the unoccupied state above the Fermi level of the later. With the electron transferring, an induced electric field impedes the transferring at the same (the net charge at the $\mathrm{Li}_{\mathrm{x}} \mathrm{FePO}_{4}(\mathrm{x}>0.5)$ side is positive, and that at the $\mathrm{Li}_{\mathrm{x}} \mathrm{FePO}_{4}$ $(x<0.5)$ side is negative). When the equilibrium is reached at the last time, a potential well for electron is formed in the medium region as shown in Figure 6.

The lithium insertion is depicted in Figure 6(a). There are two points mentioned here: the first is that accompanied with the lithium insertion, the electron must be added into the system when the reaction from $\mathrm{Fe}^{3+}$ to $\mathrm{Fe}^{2+}$ takes place; the second is that the collection of elections in the potential well could attract the lithium ion in electrolyte concentrating close to $\mathrm{Li}_{\mathrm{x}} \mathrm{FePO}_{4}(\mathrm{x}<0.5)$. Then the electron number adopted in the potential well and the distribution highly affect the lithium insertion. When the electron number in the well is small, the highest energy of the electrons is labeled with $a$ (shown in the figure), the electrons distribute in a region with the width of $D_{a}$ along (100) direction, then the width of the channel for lithium insertion also is $D_{a}$. If the electron number increases, the width of channel also increases, as the $D_{b}$ which is shown in the figure. Then the ability to transfer the electron in the out circuit into the potential well is very important for the lithium insertion.
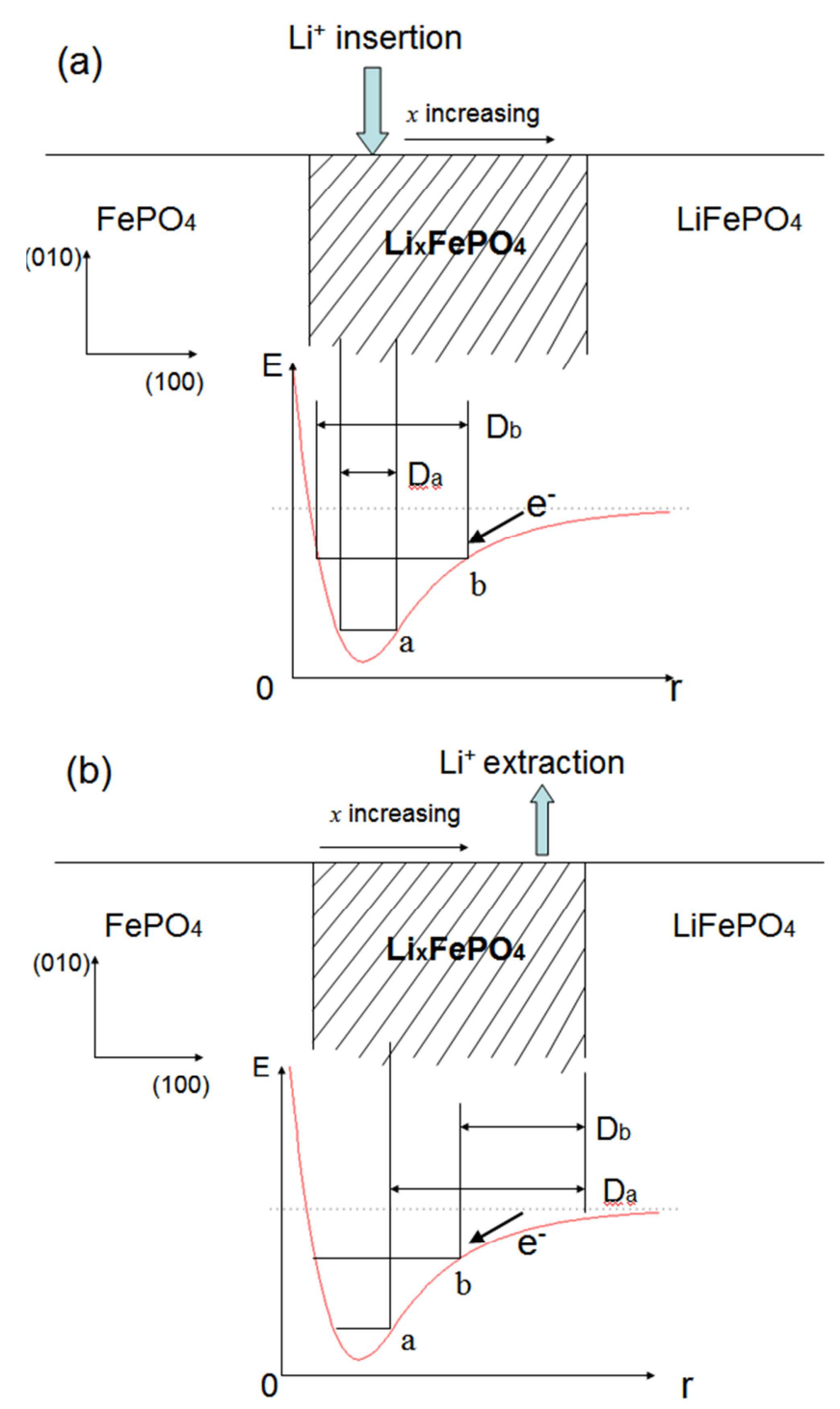

Figure 6. (a) the forming of the electron potential well in the medium region and the lithium insertion modeling; (b) the lithium extraction modeling.

The lithium extraction is different from the insertion, and is depicted in Figure 6(b). There as also two points mentioned: the first is that accompanied with the lithium extraction, the electron must be removed from the system when the reaction from $\mathrm{Fe}^{2+}$ to $\mathrm{Fe}^{3+}$ takes place; the second is that the Coulomb repulsion in the region of $\mathrm{Li}_{x} \mathrm{FePO}_{4}(x>0.5)$ with net positive charge could accelerates the lithium extraction into the electrolyte. Then the lithium extraction arises at side of $\mathrm{Li}_{\mathrm{x}} \mathrm{FePO}_{4}(\mathrm{x}>0.5)$, and with a lithium extracted, an electron falls into the potential well. The width of the channel of lithium extraction (as $D_{a}$ and $D_{b}$ shown in the figure) depends on the number of the electrons in the well, and the former increase with the later decreasing. Then the ability to transport the electron from the potential well to the out circuit is also very important for the lithium extraction.

The common way to improve the electron conductivity of 
$\mathrm{LiFePO}_{4}$ is carbon coating. While relative to the scale of the medium region, the carbon particle, even the nanoscale particle, is too large, and could not contact the region, which play key role to insert or extract lithium, properly. As shown in Figure 7(a), the medium region is just at the interspace between the carbon particle, and the electrons have to be transferred through the $\mathrm{LiFePO}_{4}$ or $\mathrm{FePO}_{4}$ phase, which has an intrinsic poor electronic conductivity.

In order to transfer electrons between the out circuit and the anode materials with a high efficiency, an electron conductor network or layer should be uniformly coated on the $\mathrm{LiFePO}_{4}$ particle, as shown in Figure 7(b). In the scenery, for lithium insertion, electron in the out circuit transfers through the conductor network are collected in the potential well in the medium, and it could attract the lithium ion in electrolyte into the anode. For extraction, the lithium goes into the electrolyte, and the electron falls into the potential well, and then transfers to the out circuit through the conductor network.

(a)
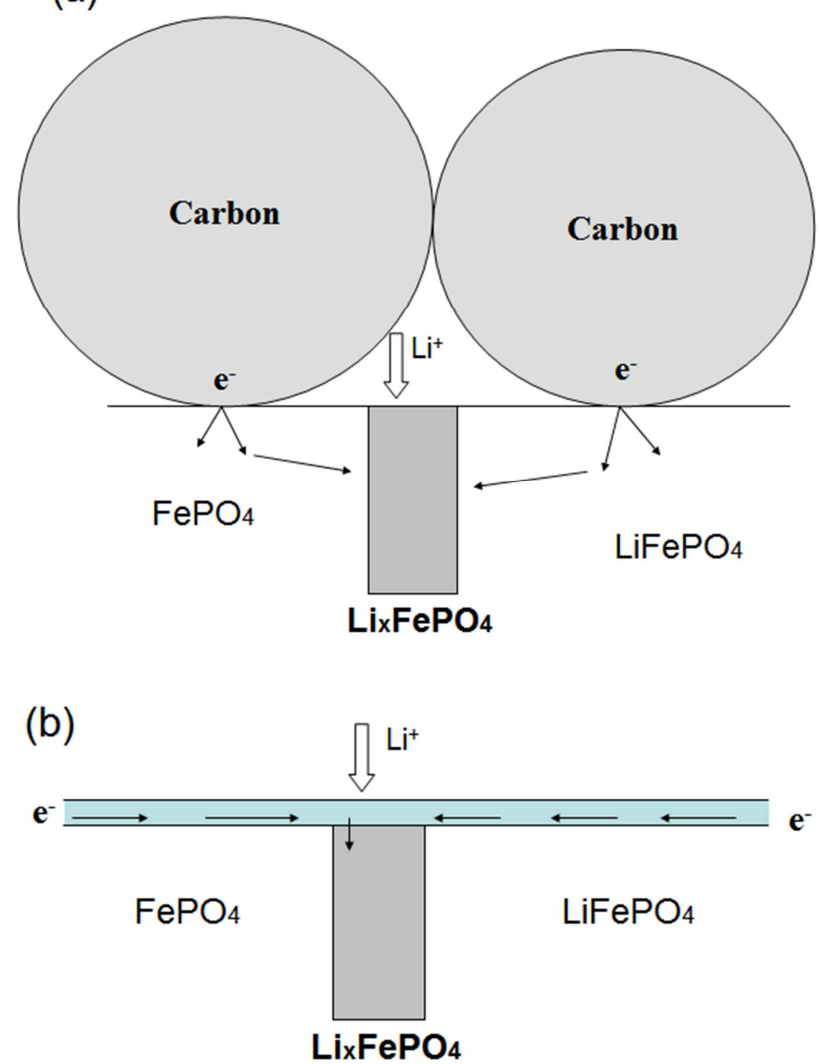

Figure 7. (a) the medium region at the interspace between two carbon particles; (b).

\section{Conclusion}

In the paper, the ab-initio calculation was applied to study the formation and electronic structure of the solid solution of $\mathrm{Li}_{\mathrm{x}} \mathrm{FePO} 4$, and a Charge/Discharge model of $\mathrm{LiFePO}_{4}$ was set up based on the calculation results. The conclusion is summarized as follows:
1) Due to the high formation energy, $\mathrm{Li}_{\mathrm{x}} \mathrm{FePO}_{4}$ separates into $\mathrm{FePO}_{4}$ and $\mathrm{LiFePO}_{4}$ in bulk system under room temperature. The single solid solution phase $\mathrm{Li}_{\mathrm{x}} \mathrm{FePO}_{4}$ could exists in the nanoscale particle, and it is due to that the relative larger lattice mismatch energy.

2) The nanoscale particle materials should have a good rating performance due to the forming of $\mathrm{Li}_{\mathrm{x}} \mathrm{FePO}_{4}$ in solid solution phase, of which the partially occupied state and the small energy gap between the VBM and the defect state could improve the intrinsic electronic conductivity.

3) In bulk materials, the medium region, which is composed of $\mathrm{Li}_{\mathrm{x}} \mathrm{FePO}_{4}$, is very narrow between the two phases $\mathrm{FePO}_{4}$ and $\mathrm{LiFePO}_{4}$. There is a electron potential well in the region, of which the bottom is at the side of $\mathrm{Li}_{\mathrm{x}} \mathrm{FePO}_{4}$ $(x<0.5)$. The number of electron in the well highly affects the lithium insertion and extraction. In order to efficiently transfer the electron between the potential well and the out circuit, an electron conductor network or layer should be coated on the $\mathrm{LiFePO}_{4}$ particle.

\section{Acknowledgements}

Yu Jun would like to acknowledge the financial support from Applied Basic Research Project of Qinghai Science and Technology Department (2017-ZJ-795). The authors acknowledge the experiment platform support from the Institute of Chemistry \& Chemical Engineering, Qinghai University for Nationalities, Xining, China.

\section{References}

[1] Hsu, K. F.; Tsay, S. Y. J. Mater. Chem. 2004, 14, 2690.

[2] Doeff, M. M.; Hu, Y.; McLarnon, F.; Kostecki, R. Electrochem. Solid-State Lett. 2003, 6, A207.

[3] Huang, H.; Yin, S. C.; Nazar, L. F. Electrochem. Solid-State Lett. 2001, 4, A170.

[4] Zaghib, K.; Striebel, K.; Guerfi, A.; Shim, J.; Armand, M.; Gauthier, M. Electrochim. Acta 2004, 50, 263.

[5] Ravet, N.; Goodenough, J. B.; Besner, S.; Simoneau, M.; Hovington, P.; Armand, M. Electrochem. Soc. Meeting Abstr. 1999, 196, 127.

[6] Dominko, R.; Gaberscek, M.; Drofenik, J.; Bele, M.; Pejovnik, S. Electrochem. Solid-State Lett. 2001, 4, A187.

[7] Barker, J.; Saidi, M. Y.; Swoyer, J. L. Electrochem. Solid State Lett. 2003, 6, A53.

[8] Chen, J.; Whittingham, S. Electrochem. Commun. 2006, 8, 855 .

[9] Yonemura, M.; Yamada, A.; Takei, Y.; Sonoyama, N.; Kanno, R., J. Electrochem. Soc. 151, A1352 (2004).

[10] Yamada, A., Koizumi, H., Sonoyama, N.; Kanno, R. Phase change in LixFePO4. Electrochem. Solid State Lett. 8, A409 (2005). 
[11] Morgan, D.; der Ven, A. V.; Ceder, G.; Electrochem. Solid-State Lett. 2004, 7, A30.

[12] Ouyang, C. Y.; Shi, S. Q.; Wang, Z. X.; Huang, X. J.; Chen, L. Q.; Phys. Rev. B, 2004, 69, 104303.

[13] Islam, M. S.; Driscoll, D.; Fisher, C.; Slater, P.; Chem. Mater., $2005,17,5085$.

[14] Nishimura, S.; Kobayashi, G.; Ohoyama, K.; Kanno, R.; Yashima, M.; Yamada, A.; Nature Mater., 2008, 7, 707.

[15] Ellis, B.; Perry, L. K.; Ryan, D. H.; Nazar, L. F.; J. Am. Chem. Soc., 2006, 128, 11416.

[16] Maxisch, T.; Zhou, F.; Ceder, G.; Phys. Rev. B, 2006, 73, 104301 .

[17] Yamada, A.; Koizumi, H.; Nishimura, S.; Sonoyama, N.; Kanno, R.; Yonemura, M.; Nakamura, T.; Kobayashi, Y.; Nature Mater., 2006, 5, 357.

[18] Kobayashi, G.; Nishimura, S. I.; Park, M. S.; Kanno, R.; Yashima, M.; Ida, T.; Yamada, A.; Adv. Funct. Mater. 2009, 19, 395.

[19] Laffont, L.; Delacourt, C.; Gibot, P.; Wu, M. Y.; Kooyman, P.; Masquelier, C.; Tarascon, J. M.; Chem. Mater. 2006, 18, 5520.

[20] G. Chen, X. Song, T. J. Richardson, Electrochem. and Solid-State Lett. 2006, 9, A295.

[21] J. L. Allen, T. R. Jow, J. Wolfenstine, Chem. Mater. 2007, 19, 2108.
[22] C. Delmas, M. Maccario, L. Croguennec, F. Le Cras, F. Weill, Nature Mater. 2008, 7, 665.

[23] C. Delacourt, P. Poizot, J. M. Tarascon, C. Masquelier, Nature Mater. 2005, 4, 254.

[24] J. Dodd, R. Yazami, B. Fultz, Electrochem. Solid-State Lett. 2006, 9, A151.

[25] P. Gibot, M. Casas-Cabanas, L. Laffont, S. Levasseur, P. Carlach, S. Hamelet, J. M. Tarascon, C. Masquelier; Nature Mater. 2008, 7, 741.

[26] Zhou, F.; Marianetti, C. A.; Cococcioni, M.; Morgan, D.; Ceder, G.; Phys. Rev. B 2004, 69, 201101.

[27] Zhou, F.; Maxisch, T.; Ceder, G.; Phys. Rev. Lett. 2006, 97, 155704.

[28] Yiyang Li. A review of recent research on nonequilibrium solid solution behavior in $\mathrm{Li}_{X} \mathrm{FePO}_{4}$. 2018, 323: 142-150.

[29] Ippei Kishida, Shota Koyama, Yoshiyuki Yokogawa. First-Principles Calculations of Ionic Conduction in Olivine-Type $\mathrm{Li}_{\mathrm{x}} \mathrm{FePO}_{4}$. 2018, 59 (7): 1062-1067.

[30] Wagiyo Honggowiranto, Honggowiranto Wagiyo, Kartini Evvy, et al. Study Performance of LiFePO4/Graphite Cylindrical Pouch Cell. 2020, 924 (1): 012036-012042. 